\title{
Reported Technical Aspects of Type II SLAP Lesion Repairs in Athletes
}

\author{
Jack W. Weick, M.D., Will B. Workman, M.D., Christopher J. Bush, M.D., \\ Katherine A. McCollum, B.S., Hiroyuki Sugaya, M.D., and Michael T. Freehill, M.D.
}

\begin{abstract}
Purpose: To systematically review the available literature to further describe and report the available data on SLAP repair techniques and the association with outcomes. Methods: A systematic review of literature was performed on manuscripts describing type II SLAP repairs in athletes. Selection criteria included studies reporting exclusively type II SLAP tears without concomitant pathology, minimum 2-year postoperative follow-up, use of anchor fixation, and return to previous level of play data available. We extracted patient outcome as well as surgical construct details from each article. Average outcomes and return to play rates were calculated and substratified further by athlete type. Return to play rates were compared by repair constructs with the Student $t$ test. Results: Initial search resulted in 107 articles. After exclusion criteria were applied, 17 articles were included in the final analysis. Overall, $84 \%$ of patients had good-to-excellent results. Of all athletes, $66 \%$ returned to previous level of play. There was significant variation in reported technique in terms of anchor number, location, material, suture type, and knotless versus knotted constructs. No significant difference was reported in outcomes in comparison of suture type $(P$-value .96$)$ or knotted versus knotless constructs $(P$-value .91). Given the significant variability in reporting, no statistical analysis was felt able to be performed on anchor location and number. Conclusions: Repair of type II SLAP tears in athletes is a difficult problem to treat with overall low return to play despite a high rate of "good" outcomes when assessed by outcome measures. Significant variability exists in surgical technique, as well as reporting of surgical technique, potentially limiting the ability to define the best or most effective technique for SLAP repair. Level of Evidence: IV, systematic review of level III and level IV studies.
\end{abstract}

A tear in the superior labrum from anterior to posterior, or SLAP, was first reported by Andrews et al. in 1985 and further defined by Snyder et al. in

From the Department of Orthopaedic Surgery, University of Michigan, Ann Arbor, Michigan, U.S.A. (J.W.W., C.J.B., K.A.M.); Walnut Creek Orthopedics $\theta$ Sports Medicine, Team Orthopedic Surgeon, Oakland Athletics, Walnut Creek, California (W.B.W.); Tokyo Sports $\theta$ Orthopaedic Clinic, Toshima, Tokyo, Japan (H.S.); and Department of Orthopaedic Surgery, Stanford University, Stanford, California, U.S.A. (M.T.F.).

The authors report the following potential conflicts of interest or sources of funding: M.T.F. reports board of trustees, medical publishing American Orthopaedic Society for Sports Medicine (AOSSM); and committee member, American Shoulder and Elbow Surgeons (ASES), AOSSM, American Academy of Orthopaedic Surgeons (AAOS), Arthroscopic Association of North America (AANA), and International Society of Arthroscopy, Knee Surgery and Orthopaedic Sports Medicine (ISAKOS). Full ICMJE author disclosure forms are available for this article online, as supplementary material.

Received April 3, 2020; accepted September 1, 2020.

Address correspondence to Jack W. Weick, M.D., Department of Orthopaedic Surgery, University of Michigan, 1500 E Medical Center Dr. Ann Arbor, MI 48109.E-mail: jackwweick@gmail.com

(C) 2021 THE AUTHORS. Published by Elsevier Inc. on behalf of the Arthroscopy Association of North America. This is an open access article under the CC BY-NC-ND license (http://creativecommons.org/licenses/by-nc-nd/4.0/).

2666-061X/20431

https://doi.org/10.1016/j.asmr.2020.09.003
1990. ${ }^{1,2}$ Type II SLAP tears, the most common type, are described as labral fraying with detachment of the superior labrum and associated biceps anchor from the glenoid (Fig 1). Overhead and contact sports are commonly described as the main risk factors for type II SLAP tears. ${ }^{3}$

Type II SLAP tears can be a significant source of pain and decreased performance in athletes, particularly those who participate in overhead activities. The superior labrum helps to restrain translation of the humerus. Loss of this restraint in a SLAP lesion may be the cause of the pain experienced in overhead athletes. ${ }^{4}$ Increased attention has been placed on appropriate treatment for these injuries in athletes to optimize return to play or sport. The incidence of SLAP repair has risen recently in the United States. ${ }^{5,6}$ Previous systematic reviews of SLAP repairs in athletes show an overall $83 \%$ good-to-excellent patient satisfaction, with a $73 \%$ return to previous level of play in all athletes. Unfortunately, the results in overhead athletes are not quite as favorable, with a reported return to play rate of only $63 \%$ and as low as $48 \%$ in baseball pitchers with return to previous performance quoted as low as $7 \%$ in pitchers. ${ }^{3,7}$ Despite the increasing rate of SLAP 


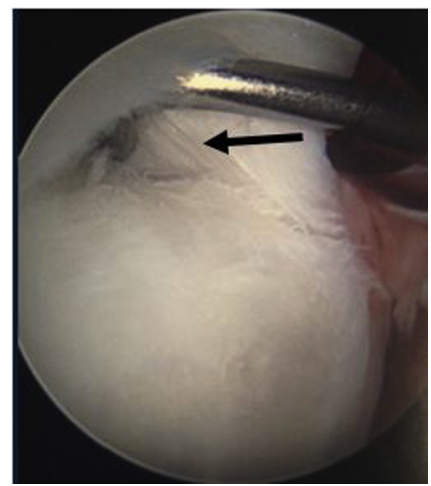

Fig 1. Intraoperative arthroscopic view of right shoulder in lateral decubitus position through posterior portal showing a type IIb SLAP tear demonstrating full-thickness tearing from below the biceps anchor insertion posteriorly (black arrow).

repairs, ${ }^{5,6}$ there is little in terms of consensus regarding optimal surgical technique. There is a relative paucity of literature comparing SLAP repair construct details such as number, type, and position of anchors, as well as type of suture material used in the repair. Furthermore, most of the literature is in the form of level III or level IV evidence.

Given poor return-to-play rates after type II SLAP repairs in athletes and lack of consensus on repair constructs and technical details, the purpose of this study sought to systematically review the available literature to further describe and report the available data on SLAP repair techniques and the association with outcomes. Specifically, we sought to compare patient satisfaction and return-to-play rates for all athletes, with emphasis on baseball athletes in isolation, based on the type of repair construct that was performed. These factors would include anchor position, number of anchors, anchor material, suture type (absorbable vs nonabsorbable), and knotted versus knotless suture anchors. We hypothesized that there would be significant variability in reported surgical techniques with no identifiable significant differences between the techniques.

\section{Methods}

\section{Search Details}

A systematic search of PubMed, MEDLINE, and Cochrane databases was performed. Our search focused on manuscripts describing type II SLAP repairs in athletes up to December 31, 2018. Criteria included studies reporting exclusively type II SLAP tears without concomitant pathology, minimum 2-year postoperative follow-up, use of anchor fixation, and return to previous level of play data available. Articles using staples or tacks for labral repair were not included so as not to skew our data, as these have generally fallen out of favor to anchor fixation.

\section{Data Extraction}

After final articles were selected based on the aforementioned search criteria, data were extracted on patient outcomes as well as surgical technique and construct details. Patient outcome data included patient satisfaction based on the outcome measure used in the respective study, return to previous level of play for all athletes (and the definition of return to play they used), return to previous level of play for overhead athletes, and return to previous level of play for baseball players when available. Surgical data extracted included anchor position, number of anchors used, anchor material, suture type used, suture technique, and whether knotted or knotless constructs were used. Level of evidence of each individual study also was identified.

\section{Statistical Analysis}

All outcome and surgical technique data available from the included articles were extracted. Satisfaction outcomes and percent return to play was calculated as weighted averages from the included studies. The return to play weighted averages were also substratified by overhead and baseball athletes as reported in the respective articles. A Student $t$ test was performed to compare the return to play rates between knotted and knotless constructs.

\section{Results}

\section{Article Selection}

The initial search generated 107 articles using our search strategy. Review of these abstracts focusing on

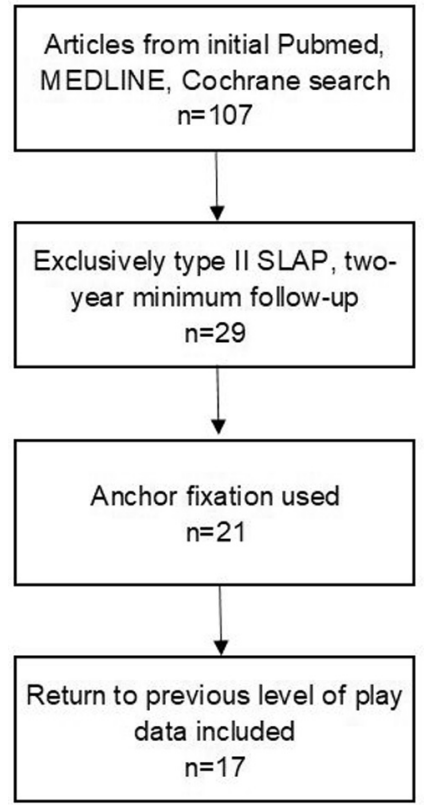

Fig 2. Flowsheet of reviewed manuscripts and inclusions/ exclusion criteria used for final selection of included manuscripts in review of type II SLAP repairs. As illustrated, 17 manuscripts met inclusion/exclusion criteria and were used for final review. 
Table 1. Surgical Outcomes

\begin{tabular}{|c|c|c|c|c|c|c|c|c|c|c|c|}
\hline \multirow[b]{2}{*}{ Study } & \multirow[b]{2}{*}{ Year } & \multicolumn{3}{|c|}{ All Patients } & \multicolumn{2}{|c|}{ Overhead Athletes } & \multicolumn{2}{|c|}{ Baseball Athletes } & \multirow[b]{2}{*}{ Outcome Measure } & \multirow[b]{2}{*}{ Study Design } & \multirow[b]{2}{*}{$\begin{array}{l}\text { Level of } \\
\text { Evidence }\end{array}$} \\
\hline & & Number & $\begin{array}{l}\% \text { Good-to- } \\
\text { Excellent } \\
\text { Satisfaction }\end{array}$ & $\begin{array}{l}\% \text { Return } \\
\text { to Play }\end{array}$ & Number & $\%$ Return to Play & Number & $\begin{array}{l}\% \text { Return } \\
\text { to play }\end{array}$ & & & \\
\hline$\overline{\text { Morgan et al. }}{ }^{8}$ & 1998 & 102 & 87 & $\mathrm{n} / \mathrm{a}$ & 53 & $\mathrm{n} / \mathrm{a}$ & 44 & 84 & UCLA & Retrospective case series & IV \\
\hline Kim et al. ${ }^{9}$ & 2002 & 34 & 94 & 76 & 18 & 22 & $\mathrm{n} / \mathrm{a}$ & $\mathrm{n} / \mathrm{a}$ & UCLA & Retrospective case series & IV \\
\hline Ide et al. ${ }^{10}$ & 2005 & 40 & 90 & 75 & 40 & 75 & 19 & 63 & Rowe & Retrospective case series & IV \\
\hline Enad et al. ${ }^{11}$ & 2007 & 27 & 89 & 77 & $\mathrm{n} / \mathrm{a}$ & $\mathrm{n} / \mathrm{a}$ & $\mathrm{n} / \mathrm{a}$ & $\mathrm{n} / \mathrm{a}$ & ASES, UCLA & Retrospective case series & IV \\
\hline Yung et al. ${ }^{12}$ & 2008 & 16 & 92 & 94 & 13 & $\mathrm{n} / \mathrm{a}$ & $\mathrm{n} / \mathrm{a}$ & $\mathrm{n} / \mathrm{a}$ & UCLA & Prospective cohort & III \\
\hline Brockmeier et al. ${ }^{13}$ & 2009 & 47 & 87 & 74 & 28 & 71 & 11 & 64 & ASES, L'Insalata & Retrospective case series & IV \\
\hline Boileau et al. ${ }^{14}$ & 2009 & 25 & 40 & 20 & 15 & $\mathrm{n} / \mathrm{a}$ & $\mathrm{n} / \mathrm{a}$ & $\mathrm{n} / \mathrm{a}$ & Constant-Murley & Prospective cohort & III \\
\hline Friel et al. ${ }^{15}$ & 2010 & 48 & 76 & 59 & 13 & 54 & 7 & 86 & $\begin{array}{l}\text { UCLA (multiple others, but } \\
\text { UCLA used for analysis) }\end{array}$ & Prospective case series & IV \\
\hline Galano et al. ${ }^{16}$ & 2010 & 22 & $\mathrm{n} / \mathrm{a}$ & 90 & 13 & 90 & 2 & $\mathrm{n} / \mathrm{a}$ & ASES, VAS, SST & Retrospective case series & IV \\
\hline Neuman et al. ${ }^{17}$ & 2011 & 30 & 93 & 67 & 30 & 67 & 21 & 52 & ASES, KJOC & Retrospective case series & IV \\
\hline Park et al. ${ }^{18}$ & 2013 & 24 & 76 & 50 & 24 & 50 & 16 & 38 & VAS, ASES & Retrospective Case series & IV \\
\hline Maier et al. ${ }^{19}$ & 2013 & 12 & $\mathrm{n} / \mathrm{a}$ & 75 & 9 & 56 & $\mathrm{n} / \mathrm{a}$ & $\mathrm{n} / \mathrm{a}$ & Constant score, SSV & Retrospective case series & IV \\
\hline Fedoriw et al. ${ }^{7}$ & 2014 & 30 & $\mathrm{n} / \mathrm{a}$ & 43 & 30 & 43 & 30 & 43 & $\begin{array}{l}\text { Return to play, return to } \\
\text { previous level of play }\end{array}$ & Retrospective case series & IV \\
\hline Ek et al. ${ }^{20}$ & 2014 & 10 & 90 & 60 & $\mathrm{n} / \mathrm{a}$ & $\mathrm{n} / \mathrm{a}$ & $\mathrm{n} / \mathrm{a}$ & $\mathrm{n} / \mathrm{a}$ & $\begin{array}{l}\text { ASES, Satisfaction score, } \\
\text { VAS }\end{array}$ & Retrospective cohort & IV \\
\hline Gilliam et al. ${ }^{21}$ & 2018 & 133 & $\mathrm{n} / \mathrm{a}$ & 64 & 133 & 64 & 133 & 64 & WOSI, VR-12 & Retrospective Case series & IV \\
\hline Reinig et al. ${ }^{22}$ & 2018 & 28 & $\mathrm{n} / \mathrm{a}$ & 33 & $\mathrm{n} / \mathrm{a}$ & $\mathrm{n} / \mathrm{a}$ & $\mathrm{n} / \mathrm{a}$ & $\mathrm{n} / \mathrm{a}$ & NAS, ASOSS, SSAS & Retrospective cohort & III \\
\hline $\begin{array}{l}* * \text { Other arm of Reinig } \\
\text { study** }\end{array}$ & & 33 & $\mathrm{n} / \mathrm{a}$ & 50 & $\mathrm{n} / \mathrm{a}$ & $\mathrm{n} / \mathrm{a}$ & $\mathrm{n} / \mathrm{a}$ & $\mathrm{n} / \mathrm{a}$ & NAS, ASOSS, SSAS & Retrospective cohort & III \\
\hline de Groot et al. ${ }^{23}$ & 2018 & 42 & $\mathrm{n} / \mathrm{a}$ & 90 & 53 & 91 & 14 & $\mathrm{n} / \mathrm{a}$ & ASES, KJOC & Retrospective case series & IV \\
\hline $\begin{array}{l}\text { **Other arm of de Groot } \\
\text { study** }\end{array}$ & & 32 & $\mathrm{n} / \mathrm{a}$ & 93 & ${ }^{* *}$ No d & stinguishing betwee & en knottec & 1/knotless & ASES, KJOC & Retrospective case series & IV \\
\hline
\end{tabular}

ASOSS, American Orthopaedic Society for Sports Medicine; ASES, American Shoulder and Elbow Surgeons; KJOC, Kerlan-Jobe Orthopaedic Clinic; n/a, not available; NAS, numerical

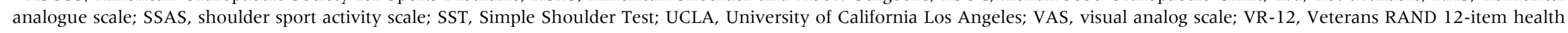
survey; WOSI, Western Ontario Shoulder Instability Index. 


\begin{tabular}{|c|c|c|c|c|c|c|c|}
\hline \multirow[b]{2}{*}{ Study } & \multirow[b]{2}{*}{ Year } & \multirow[b]{2}{*}{$\begin{array}{l}\text { Fixation } \\
\text { Type }\end{array}$} & \multicolumn{5}{|c|}{ Anchor Construct Detail } \\
\hline & & & Anchor Position & Anchor Type & $\begin{array}{l}\text { Anchor } \\
\text { Number }\end{array}$ & Suture Type & $\begin{array}{l}\text { Knotted vs } \\
\text { Knotless }\end{array}$ \\
\hline$\overline{\text { Morgan et al. }}{ }^{8}$ & 1998 & Anchor & $\begin{array}{l}\text { Anterior and/or } \\
\text { posterior depending } \\
\text { on tear }\end{array}$ & Metal & 2 & $81 \mathrm{w} / \mathrm{PDS}, 21 \mathrm{w} / \mathrm{ETHIBOND}$ & Knotted \\
\hline Kim et al. ${ }^{9}$ & 2002 & Anchor & Biceps insertion & Metal & $\begin{array}{l}1 \text { w/more "as } \\
\text { needed" }\end{array}$ & ETHIBOND & Knotted \\
\hline Ide et al. ${ }^{10}$ & 2005 & Anchor & 1 anterior, 1 posterior & Biocomposite & $\begin{array}{c}2 \text { w/more "as } \\
\text { needed" }\end{array}$ & ETHIBOND & Knotted \\
\hline Enad et al. ${ }^{11}$ & 2007 & Anchor & $\begin{array}{l}\text { Anterior and/or } \\
\text { posterior depending } \\
\text { on tear }\end{array}$ & Biocomposite & $\mathrm{n} / \mathrm{a}$ & $\mathrm{n} / \mathrm{a}$ & Knotted \\
\hline Yung et al. ${ }^{12}$ & 2008 & Anchor & $\begin{array}{l}\text { Anterior and/or } \\
\text { posterior depending } \\
\text { on tear }\end{array}$ & Biocomposite & $2-4$ & PDS & Knotted \\
\hline Brockmeier et al. ${ }^{13}$ & 2009 & Anchor & $\begin{array}{l}\text { Anterior unless tear } \\
\text { extends too far } \\
\text { posteriorly }\end{array}$ & $\mathrm{n} / \mathrm{a}$ & $\begin{array}{l}1 \mathrm{w} / \mathrm{more} \text { "as } \\
\text { needed" }\end{array}$ & Nonabsorbable & Knotted \\
\hline Boileau et al. ${ }^{14}$ & 2009 & Anchor & 1 anterior, 1 posterior & Biocomposite & 2 & $\mathrm{n} / \mathrm{a}$ & Knotted \\
\hline Friel et al. ${ }^{15}$ & 2010 & Anchor & $\begin{array}{l}\text { Under biceps insertion } \\
\text { and posterior }\end{array}$ & Biocomposite & 2 & $\mathrm{n} / \mathrm{a}$ & Knotted \\
\hline Galano et al. ${ }^{16}$ & 2010 & Anchor & Posterior & Biocomposite & $\begin{array}{l}1 \mathrm{w} / \text { more "as } \\
\text { needed" }\end{array}$ & $\mathrm{n} / \mathrm{a}$ & Knotted \\
\hline Neuman et al. ${ }^{17}$ & 2011 & Anchor & $\begin{array}{l}\text { Anterior and/or } \\
\text { posterior depending } \\
\text { on tear }\end{array}$ & Biocomposite & $1-4$ & $\mathrm{n} / \mathrm{a}$ & Knotted \\
\hline Park et al. ${ }^{18}$ & 2013 & Anchor & $\begin{array}{l}1 \text { anterior, } 1 \text { posterior } \\
\text { with additional } \\
\text { posterior as needed }\end{array}$ & Biocomposite & $2-4$ & Nonabsorbable and absorbable & Knotted \\
\hline Maier et al. ${ }^{19}$ & 2013 & Anchor & $\begin{array}{l}\text { Anterior and/or } \\
\text { posterior depending } \\
\text { on tear }\end{array}$ & Biocomposite & $1-2$ & FiberWire & Knotted \\
\hline Fedoriw et al. ${ }^{7}$ & 2014 & Anchor & $\mathrm{n} / \mathrm{a}$ & $\mathrm{n} / \mathrm{a}$ & $\mathrm{n} / \mathrm{a}$ & $\mathrm{n} / \mathrm{a}$ & $\mathrm{n} / \mathrm{a}$ \\
\hline Ek et al. ${ }^{20}$ & 2014 & Anchor & $\begin{array}{l}\text { Beneath biceps } \\
\text { insertion, or just } \\
\text { posterior }\end{array}$ & Biocomposite & 1 & PDS & Knotted \\
\hline Gilliam et al. ${ }^{21}$ & 2018 & Anchor & $\mathrm{n} / \mathrm{a}$ & $\mathrm{n} / \mathrm{a}$ & $\mathrm{n} / \mathrm{a}$ & $\mathrm{n} / \mathrm{a}$ & Knotted \\
\hline Reinig et al. ${ }^{22}$ & 2018 & Anchor (knotted) & 1 anterior, 1 posterior & $\mathrm{n} / \mathrm{a}$ & 2 & Nonabsorbable & Knotted (vs knotless) \\
\hline $\begin{array}{l}* * \text { Other arm of Reinig } \\
\text { study**}\end{array}$ & & Anchor (knotless) & 1 anterior, 1 posterior & $\mathrm{n} / \mathrm{a}$ & 2 & Nonabsorbable & Knotless (vs knotted) \\
\hline de Groot et al. ${ }^{23}$ & 2018 & Anchor (knotted) & Posterior & Biocomposite & $1-4$ & FiberWire & Knotted (vs knotless) \\
\hline $\begin{array}{l}{ }^{* *} \text { Other arm of de } \\
\text { Groot study }{ }^{* *}\end{array}$ & & Anchor (knotless) & Posterior & Biocomposite & $1-4$ & Labral tape/suture tape & Knotless (vs knotted) \\
\hline
\end{tabular}


Table 3. Summary Table

Number of articles reviewed

107

Number of articles reviewed

Articles reporting number of anchors, \%

Articles reporting position of anchors, \%

Articles reporting type of anchor, \%

Articles reporting type of suture, \%

studies reporting exclusively type II SLAP tears without concomitant pathology and with minimum 2-year postoperative follow-up resulted in 29 articles. Eliminating studies that did not use suture anchors left 21 articles (1 used staple, 7 used tacks). Of these, 4 articles did not have any return-to-play data reported. This left us with a final article total of 17 for the review. A flowsheet of the article selection is illustrated in Fig 2.

\section{Surgical Outcomes}

Surgical outcomes for all studies are included in Table $1 .^{7-23}$ Overall, $84 \%$ of the patient population had "good-to-excellent" results based on the postoperative outcome measures used in the respective studies. In all athletes, $66 \%$ returned to the previous level of play. Duration of return to play was not clearly defined in the included manuscripts. One article (Morgan et al. ${ }^{8}$ ) did not provide return to play data for all athletes, this was only reported for baseball players. In the articles that subdivided patients into overhead athletes and baseball players, $65 \%$ of all overhead athletes and $63 \%$ of baseball players were reported to return to their previous level of play. Only four articles specifically subdivided pitchers. In these articles, $65 \%$ of pitchers returned to their previous level of play.

\section{Surgical Techniques}

As illustrated in Table 2, considerable variation existed in reported surgical techniques. ${ }^{7-23}$ Reported anchor position varied from anterior and/or posterior depending on tear (5/17), 1 anchor anterior and 1 posterior $(4 / 17)$, posterior $(2 / 17)$, anterior unless the tear extends too far posteriorly $(1 / 17)$, at the biceps insertion (1/17), at the biceps insertion or posterior (1/ 17), under biceps insertion and posterior (1/17), or not reported (2/17). Number of anchors varied from 2 anchors (4/17), 1 anchor with more "as needed" (3/17), 1-4 anchors (2/17), not reported (3/17), 1 anchor (1/ 17), 2 anchors with more "as needed" (1/17), 2-4 anchors (2/17), or $1-2$ anchors (1/17). No specifics were provided as to how many patients within each study received a certain number of anchors if a range was provided in the surgical methods. In the manuscripts that included ranges of anchors, none of the articles described the exact number of patients who received each number of anchor (i.e., \% of patients with 1 anchor, \% with 2 anchors, etc.). Anchor material reported included 12 of 17 manuscripts used biocomposite anchors, 2 of 17 used metal anchors, and 3 did not report the material used or if the anchor was the biocomposite or PEEK (polyether ether ketone) version of the anchor. Suture type was not reported in 7 of 17 articles. Of the remaining, suture options included absorbable sutures such as PDS (\#1) and nonabsorbable sutures such as ETHIBOND (\#2), FiberWire (\#2), and labral tape. Two studies reported only using absorbable sutures. Six studies reported only using nonabsorbable sutures. One study used nonabsorbable suture in $21 \%$ of patients and absorbable sutures in $79 \%$ of patients. Two studies compared knotted and knotless suture options and, therefore, had 2 separate study arms. One study did not report if they used a knotted or knotless construct. The remaining 12 studies used knotted suture construct. No studies looked at knotless sutures in isolation without directly comparing to knotted constructs. In total, 7 of 17 of the studies reported suture technique. Of these, all included simple passes. One study used horizontal mattress and simple technique depending on surgeon and tear type. ${ }^{19}$ One study used lasso loop or simple sutures. ${ }^{11}$ Table 3 shows a summary of reported data in the included studies.

In comparison of suture type, there was a $90 \%$ goodto-excellent satisfaction rate in the nonabsorbable population and $91 \%$ in the absorbable population $(P$ value .96). There was a $75 \%$ return to previous level of play rate in the nonabsorbable population and $81 \%$ in the absorbable population. This difference was not statistically significant ( $P$-value .46). Comparing knotted versus knotless constructs, we found there were no data available in terms of patient satisfaction with the knotless constructs. However, with regards to return to previous level of play, $67 \%$ of patients with the knotted construct and $71 \%$ with the knotless construct returned to their previous level of play. This difference was also not statistically significant $(P$-value $.91)$. Given the high variability in anchor number and position, no further statistical analysis could be performed on the anchor details.

\section{Discussion}

This study provides further evidence of the overall lower return to play rates after type II SLAP repairs in this population. More importantly, this study highlights the significant variability in surgical techniques and constructs used for this operation and thus questions whether surgical technique could provide a more predictable and better chance at successful return to play. Type II SLAP tears have traditionally been difficult to treat in athletes, particularly overhead throwing athletes. The outcomes of nonoperative management in throwing athletes have been shown to be inferior to those in nonthrowing athletes. ${ }^{24}$ High levels of success 


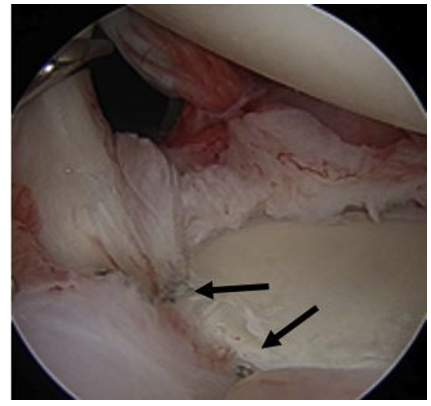

Fig 3. Intraoperative arthroscopic image of right shoulder in lateral decubitus position through a posterior portal during type II slap repair. Two knotless anchors with heavy \#2 nonabsorbable suture passed in a simple fashion posterior to the biceps anchor insertion (black arrows).

for surgical treatment of type II SLAP tears were reported early in the general population, as well as military recruits, with up to $97 \%$ "good-to-excellent" results. ${ }^{8,11}$ However, results for high-level athletes and overhead athletes have traditionally been less successful, which has been echoed by our review.,25

In the studies included in our review, anchor construct detail was extremely variable. Only 7 of the $17(41 \%)$ manuscripts gave specific descriptions of anchor position on the glenoid, as well as number of anchors used. The remainder of the articles generally provided vague descriptions of anchor placement location. Some articles provided a range of anchors; however, these articles did not generally provide rational for number of anchors used or the location, nor did they provide a breakdown of the number of patients with different anchor number and location combinations. Although these lesions can be variable and require patient-specific approach for repair, which can lead to requirements of different anchor locations and number of anchors, there are certain well-established biomechanical principles for type II SLAP repairs. Proper anchor placement can have a significant impact on shoulder biomechanics, and could be, arguably, the most important aspect of SLAP repairs. Morgan et al. ${ }^{26}$ showed in a cadaveric model that there was no biomechanical advantage to an anterior suture anchor, and argued that 2 posterior suture anchors is biomechanically preferable. McCulloch et al. ${ }^{27}$ used a cadaveric throwing model to show that repair of type II SLAP tears with an anterior anchor resulted in a loss of $2.0^{\circ}$ of external rotation. Although this could be reasoned to not be clinically significant, this loss could be extremely detrimental to an overhead throwing athlete. However, 2 degrees of loss depending on how this was measured could be in the standard deviation of error and therefore might not be of relevance. Of note, 9 of the 17 articles $(53 \%)$ included in our study reported anterior anchor placement in at least a portion of their patient
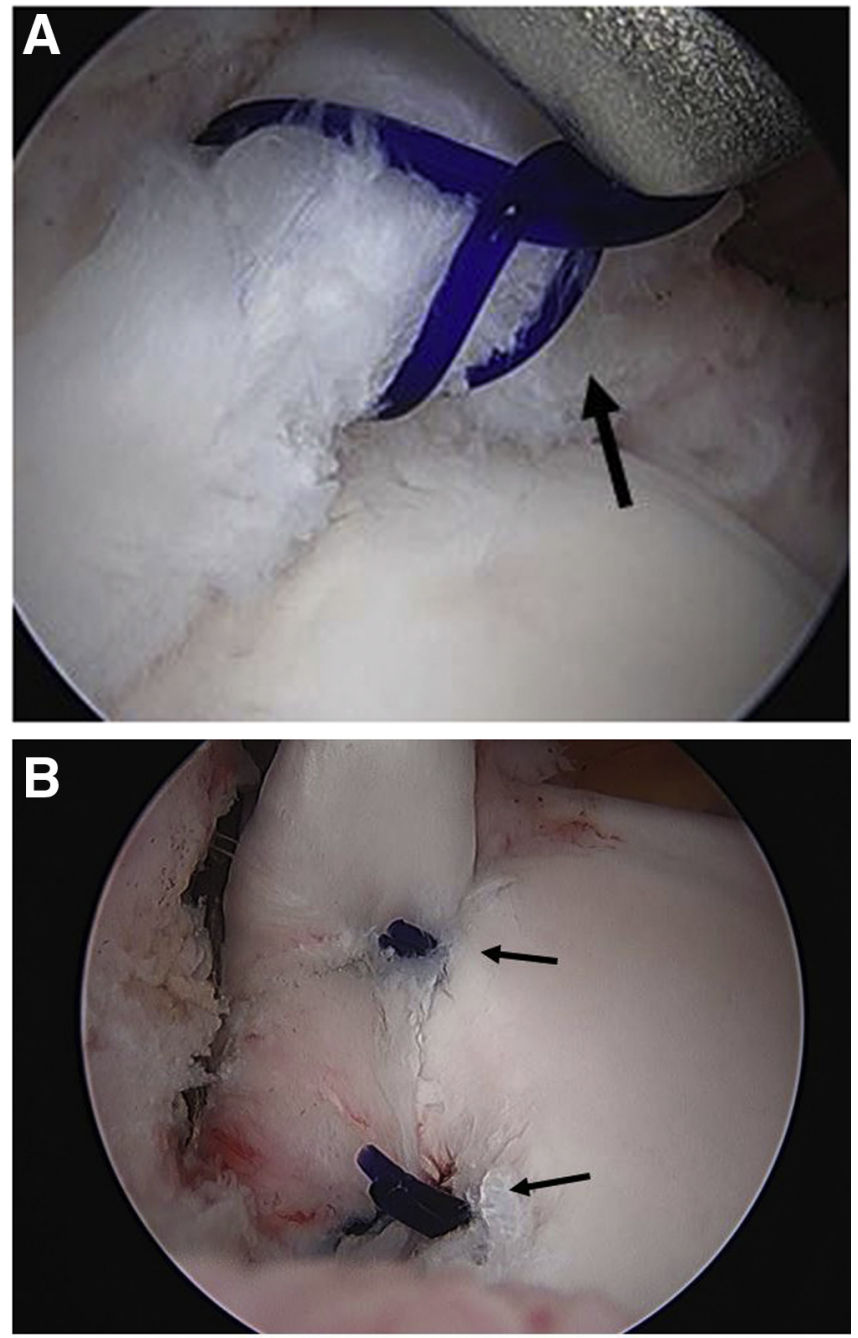

Fig 4. (A) Intraoperative arthroscopic image of right shoulder in lateral decubitus position through a posterior portal during type II SLAP repair. \# I PDS absorbable suture has been passed in a luggage tag technique (black arrow). (B) Intraoperative arthroscopic image of right shoulder in lateral decubitus position through a posterior portal during type II SLAP repair. Two knotless anchors with \#l PDS passed in luggage tag technique and placed posterior to the biceps anchor insertion (black arrows). The elasticity of the suture could be less constraining on the labrum and luggage tag allow the labrum to position itself in a more anatomic fashion. (PDS, polydioxanone.)

population. Although current dogma believes this anterior based anchor could overconstrain a throwers ability to reach the needed external rotation to be effective, the poor rates of return of throwers with anchors only posterior to the biceps anchor may be grounds to rethink this traditionally held belief. Additionally, in our experience, it is rare that a SLAP repair would require more than 3 anchors. Four of the 17 $(23.5 \%)$ included articles mentioned using up to 4 anchors in certain patients. 
It has been hypothesized that, in type II SLAP repairs, knotted anchors are bulkier and can abrade the rotator cuff or internally impinge which may lead to postoperative or ongoing pain. There are also concerns regarding the consistency of tensioning during knot tying with these constructs. ${ }^{23,28}$ Some recent studies have attempted to directly compare knotted and knotless suture anchors. ${ }^{22,23}$ Neither of these studies reported significant differences in return to sport between the knotted and knotless anchors. However, Reinig et al. ${ }^{22}$ did report significantly improved range of motion postoperatively in the knotless group. Given the low population size in each of these studies, it is possible that a difference would be seen in return to play rates with a larger population given the improved range of motion in the knotless group, but this requires further study. Dines et al. ${ }^{29}$ showed that a knotless anchor technique can help recreate the normal anatomy of the superior labrum. They hypothesized that this may be beneficial to overhead throwing athletes by recreating the normal glenohumeral space and preventing potential discomfort caused by a bulky knot. In a biomechanical model, Uggen et al. ${ }^{30}$ showed no difference in yield load or load to failure in knotless vs. knotted anchors. A question that deserves answering is the type of suture used. An absorbable suture such a polydioxanone has more elasticity than a \#2 nonabsorbable anchor and potentially could allow healing in a more anatomical or biologically friendly manner without the concern for knot impingement. However, broader sutures such as labral tape may have the benefit of increased strength while restoring labral height and allowing for a broader surface of compression, thus limiting "cut-through" on the labrum. ${ }^{31}$ Furthermore, the technique or type of suture passage could be important and not often reported upon (Figs 3 and $4 \mathrm{~A}$ and $\mathrm{B}$ ).

Future directions in the study of type II SLAP tears should be focused on both continued biomechanical studies, as well as direct clinical comparisons between these different techniques. Quality randomized controlled trials comparing different surgical techniques would be the most optimal form of study but may be difficult, given the number of variables and relatively small overall population affected by this pathology. Nonetheless, improved consistency and thoroughness in reporting clinical results would be beneficial for quality reviews of the effectiveness of differing surgical techniques. Other surgical details such as anchor position, suture passage technique, and postoperative rehabilitation protocols should be included, as they also may contribute to surgical outcomes. Furthermore, increased focus on repair strategies for subtypes of type II SLAP tears (type II-A, II-B, II-C), as well as type IX SLAP tears is important. The included manuscripts did not delineate exact subtype of SLAP tear. However, these details may additionally be important as the amount of posterior extension of the tear and treatment strategies of repair while avoiding inhibiting a thrower's ability to get to the late-cocking position of the throwing motion and limiting athletes' ability to return to their prior level of play is of the utmost importance.

\section{Limitations}

This study was not without limitations. Significant variability in reported techniques in the included studies prevented any meaningful statistical comparisons between different surgical techniques. The studies included also spanned approximately 20 years, which can result in variable indications for surgery and surgical tools and techniques available at the time of each respective study. In addition, different outcome measures were used in these studies to define "good-toexcellent" results. Given that most studies included involved a low number of patients, it is possible that our study is underpowered to find statistical differences in surgical techniques. It should be noted that general shoulder outcome scores such as American Shoulder and Elbow Surgeons, Constant, etc., are not as reliable for the overhead athlete. Only 2 of the included articles used the Kerlan-Jobe Orthopaedic Clinic, which more specifically is tailored for overhead athletes. ${ }^{32}$

\section{Conclusions}

Repair of type II SLAP tears in athletes is a difficult problem to treat with overall low return to play despite a high rate of "good" outcomes when assessed by outcome measures. Significant variability exists in surgical technique, as well as reporting of surgical technique potentially limiting the ability to define the best or most effective technique for SLAP repair.

\section{References}

1. Andrews JR, Carson WG, McLeod WD. Glenoid labrum tears related to the long head of the biceps. Am J Sports Med 1985;13:337-341.

2. Snyder SJ, Karzel RP, Del Pizzo W, Ferkel RD, Friedman MJ. SLAP lesions of the shoulder. Arthroscopy 1990;6:274-279

3. Sayde WM, Cohen SB, Ciccotti MG, Dodson CC. Return to play after Type II superior labral anterior-posterior lesion repairs in athletes: A systematic review. Clin Orthop Relat Res 2012;470:1595-1600.

4. Chhadia AM, Goldberg BA, Hutchinson MR. Abnormal translation in SLAP lesions on magnetic resonance imaging abducted externally rotated view. Arthroscopy 2010;26:19-25.

5. Weber SC, Martin DF, Seiler JG, Harrast JJ. Superior labrum anterior and posterior lesions of the shoulder: Incidence rates, complications, and outcomes as reported by American Board of Orthopedic Surgery. Part II candidates. Am J Sports Med 2012;40:1538-1543. 
6. Zhang AL, Kreulen C, Ngo SS, Hame SL, Wang JC, Gamradt SC. Demographic trends in arthroscopic SLAP repair in the United States. Am J Sports Med 2012;40: 1144-1147.

7. Fedoriw WW, Ramkumar P, McCulloch PC, Lintner DM. Return to play after treatment of superior labral tears in professional baseball players. Am J Sports Med 2014;42: 1155-1160.

8. Morgan CD, Burkhart SS, Palmeri M, Gillespie M. Type II SLAP lesions: Three subtypes and their relationships to superior instability and rotator cuff tears. Arthroscopy 1998; 14:553-565.

9. Kim S-H, Ha K-I, Kim S-H, Choi H-J. Results of arthroscopic treatment of superior labral lesions. J Bone Joint Surg Am 2002;84:981-985.

10. Ide J, Maeda S, Takagi K. Sports activity after arthroscopic superior labral repair using suture anchors in overheadthrowing athletes. Am J Sports Med 2005;33:507-514.

11. Enad JG, Gaines RJ, White SM, Kurtz CA. Arthroscopic superior labrum anterior-posterior repair in military patients. J Shoulder Elbow Surg 2007;16:300-305.

12. Yung PS-H, Fong DT-P, Kong M-F, et al. Arthroscopic repair of isolated type II superior labrum anteriorposterior lesion. Knee Surg Sports Traumatol Arthrosc 2008;16:1151-1157.

13. Brockmeier SF, Voos JE, Williams RJ, et al. Outcomes after arthroscopic repair of type-II SLAP lesions. J Bone Joint Surg Am 2009;91:1595-1603.

14. Boileau P, Parratte S, Chuinard C, Roussanne Y, Shia D, Bicknell R. Arthroscopic treatment of isolated type II SLAP lesions: Biceps tenodesis as an alternative to reinsertion. Am J Sports Med 2009;37:929-936.

15. Friel NA, Karas V, Slabaugh MA, Cole BJ. Outcomes of type II superior labrum, anterior to posterior (SLAP) repair: Prospective evaluation at a minimum two-year follow-up. J Shoulder Elbow Surg 2010;19:859-867.

16. Galano GJ, Ahmad CS, Bigliani L, Levine W. Percutaneous SLAP lesion repair technique is an effective alternative to portal of Wilmington. Orthopedics 2010;33:803.

17. Neuman BJ, Boisvert CB, Reiter B, Lawson K, Ciccotti MG, Cohen SB. Results of arthroscopic repair of type II superior labral anterior posterior lesions in overhead athletes: Assessment of return to preinjury playing level and satisfaction. Am J Sports Med 201 1;39:1883-1888.

18. Park J-Y, Chung S-W, Jeon S-H, Lee J-G, Oh K-S. Clinical and radiological outcomes of type 2 superior labral anterior posterior repairs in elite overhead athletes. Am J Sports Med 2013;41:1372-1379.

19. Maier D, Jaeger M, Ogon P, Bornebusch L, Izadpanah K, Suedkamp NP. Suture anchors or transglenoidal sutures for arthroscopic repair of isolated SLAP-2 lesions? A matched-pair comparison of functional outcome and return to sports. Arch Orthop Trauma Surg 2013;133: 227-235.

20. Ek ETH, Shi LL, Tompson JD, Freehill MT, Warner JJP. Surgical treatment of isolated type II superior labrum anterior-posterior (SLAP) lesions: Repair versus biceps tenodesis. J Shoulder Elbow Surg 2014;23:1059-1065.

21. Gilliam BD, Douglas L, Fleisig GS, et al. Return to play and outcomes in baseball players after superior labral anteriorposterior repairs. Am J Sports Med 2018;46:109-115.

22. Reinig Y, Welsch F, Hoffmann R, et al. Outcome of arthroscopic SLAP repair using knot-tying-suture anchors compared with knotless-suture anchors in athletes. Arch Orthop Trauma Surg 2018;138:1273-1285.

23. de Groot SJ, Arner JW, Smith CN, Bradley JP. Arthroscopic SLAP IIb repair using knot-tying versus knotless suture anchors: Is there a difference? Am J Orthop $2018 ; 47$.

24. Edwards SL, Lee JA, Bell J-E, et al. Nonoperative treatment of superior labrum anterior posterior tears: Improvements in pain, function, and quality of life. Am J Sports Med 2010;38:1456-1461.

25. Thayaparan A, Yu J, Horner NS, Leroux T, Alolabi B, Khan M. Return to sport after arthroscopic superior labral anterior-posterior repair: A systematic review. Sports Health 2019;11:520-527.

26. Morgan RJ, Kuremsky MA, Peindl RD, Fleischli JE. A biomechanical comparison of two suture anchor configurations for the repair of type II SLAP lesions subjected to a peel-back mechanism of failure. Arthroscopy 2008;24: 383-388.

27. McCulloch PC, Andrews WJ, Alexander J, Brekke A, Duwani S, Noble P. The effect on external rotation of an anchor placed anterior to the biceps in type 2 SLAP repairs in a cadaveric throwing model. Arthroscopy 2013;29:18-24.

28. Hanypsiak BT, DeLong JM, Simmons L, Lowe W, Burkhart S. Knot Strength Varies Widely Among Expert Arthroscopists. Am J Sports Med 2014;42:1978-1984.

29. Dines JS, Elattrache NS. Horizontal mattress with a knotless anchor to better recreate the normal superior labrum anatomy. Arthroscopy 2008;24:1422-1425.

30. Uggen C, Wei A, Glousman RE, et al. Biomechanical comparison of knotless anchor repair versus simple suture repair for type II SLAP lesions. Arthroscopy 2009;25: 1085-1092.

31. Calcei JG, Boddapati V, Altchek DW, Camp CL, Dines JS, Diagnosis and treatment of injuries to the biceps and superior labral complex in overhead athletes. Curr Rev Musculoskelet Med 2018;11:63-71.

32. Alberta FG, ElAttrache NS, Bissell S, et al. The development and validation of a functional assessment tool for the upper extremity in the overhead athlete. Am J Sports Med 2010;38:903-911. 